\title{
Contribuições do Arduino no ensino de Física: uma revisão sistemática de publicações na área do ensino ${ }^{+*}$
}

\author{
Michele Maria Paulino Carneiro Moreira \\ Mestranda em Ensino de Ciências e Matemática \\ Programa de Pós-Graduação em Ensino de Ciências e Matemática \\ Instituto Federal de Educação, Ciência e Tecnologia do Ceará - IFCE \\ Mairton Cavalcante Romeu ${ }^{1}$ \\ Programa de Pós-Graduação em Ensino de Ciências e Matemática \\ Instituto Federal de Educação, Ciência e Tecnologia do Ceará - IFCE \\ Francisco Regis Vieira Alves ${ }^{1}$ \\ Programa de Pós-Graduação em Ensino de Ciências e Matemática \\ Instituto Federal de Educação, Ciência e Tecnologia do Ceará - IFCE \\ Francisco Roberto Oliveira da Silva ${ }^{1}$ \\ Instituto Federal de Educação, Ciência e Tecnologia do Ceará - IFCE \\ Fortaleza-CE
}

\section{Resumo}

Este trabalho apresenta uma revisão da literatura sobre o uso do Arduino no ensino de Física, realizada através da consulta a artigos publicados nas principais revistas de ensino de Ciências do Brasil. A pesquisa concentrou-se nas contribuições do uso do Arduino direcionados ao ensino de Física e resultou numa amostra de 20 artigos. Os trabalhos consultados foram classificados em duas categorias: propostas didáticas testadas em sala de aula, e propostas didáticas para aplicação em sala de aula. Além disso, são apontados os principais objetivos esperados pelas práticas, as quais são: inovação dos laboratórios didáticos, interdisciplinaridade e contextualização, potencializar a aprendizagem dos con-

\footnotetext{
${ }^{+}$Contributions of the Arduino in the Teaching of Physics: a systematic review of publications in the area of education

* Recebido: maio de 2018. Aceito: outubro de 2018.

${ }^{1}$ E-mail: michelepaulino12@gmail.com; mairtoncavalcante@gmail.com; fregis@gmx.fr; roberto.refex@gmail.com
} 
ceitos físicos, tornar as aulas atraentes e motivadoras, obtenção de dados e difusão do Arduino. É possível constatar que, apesar dessa tecnologia ser relativamente nova, já existem muitas publicações na área, com possíveis aplicações no ensino de Física. A maioria, com propostas metodológicas voltadas para a prática experimental, bem como, a automatização dos laboratórios didáticos. Em geral, nas práticas experimentais abordadas foram obtidos resultados de pesquisa satisfatórios, porém pontuais. Embora sejam divulgadas muitas propostas didáticas inovadoras, ainda há poucos trabalhos que mostram dados quanto à aprendizagem de conceitos físicos por meio da aplicação dos recursos já citados, em sala de aula.

Palavras-chave: Arduino; Ensino de Física, Prática Experimental, Novas Tecnologias.

\section{Abstract}

This paper presents a review of the literature on the use of Arduino in Physics teaching, conducted through the consultation of articles published in the main Brazilian science teaching journals. The research focused on the contributions of the use of Arduino directed to the teaching of Physics and resulted in a sample of 20 articles. The collected papers were classified into two categories: didactic proposals tested in the classroom, and didactic proposals for application in the classroom. In addition, the main objectives expected by the practices are: innovation of the didactic laboratories, interdisciplinarity and contextualization, potentiate the learning of the physical concepts, make classes attractive and motivating, obtaining data and dissemination of the Arduino. It is possible to observe that, although this technology is relatively new, there are already many publications in the area, with possible applications in physics teaching. Most, with metrological proposals focused on experimental practice, as well as, the automation of didactic laboratories. In general, in the experimental practices approached, satisfactory but punctual results were obtained. Although many innovatory didactic proposals have been made public, there are still few studies that show data regarding the learning of physical concepts through the application of the aforementioned resources in the classroom. 
Keywords: Arduino; Physics Teaching; Experimental Practice; New Technologies.

\section{Introdução}

O crescente avanço das tecnologias tem influenciado nos meios educacionais, levando a uma necessidade constante de capacitação e atualização dos professores. E ao mesmo tempo, tem possibilitado novas abordagens dos temas da Física de forma mais interativa.

O Arduino tem se mostrado como uma tecnologia versátil e de simples utilização por professores e alunos, por ser uma plataforma eletrônica de código aberto baseada em hardware e software fáceis de usar, e com um custo relativamente baixo. Diante disto, apresentamos as principais contribuições sobre a aplicação do Arduino como recurso motivador para o ensino e aprendizagem dos alunos, fornecendo aos professores recurso didático para aulas experimentais no ensino de Física.

No meio escolar, esta ferramenta pode ser utilizada na experimentação para construir instrumentos científicos de baixo custo, e para provar princípios físicos por professores e alunos. Dessa forma, podem-se inicializar os alunos no ambiente de programação e robótica.

Este artigo de revisão bibliográfica partiu da necessidade da inserção de novas tecnologias no ensino de Física, que subsidiem o professor na abordagem dos temas em sala de aula. Assim, ao oferecer novas possibilidades, o processo de ensino-aprendizagem pode ser enriquecido e consolidado, ampliando a obtenção de novos conhecimentos.

Foi realizada a consulta de artigos em revistas da área de ensino de Ciências e de Física no Brasil, abrangendo àqueles direcionados para o ensino de Física no nível médio da educação básica. Nestes artigos, diversos temas da Física foram abordados, com enfoque na prática experimental, utilizando o Arduino para obtenção de dados, além de outras aplicações.

\section{Metodologia}

Este trabalho foi efetuado através de uma pesquisa exploratória, com vista a realizar um estudo por meio da coleta de artigos sobre o tema proposto, e analisar os resultados das pesquisas, considerações e conclusões feitas por diversos autores à cerca do uso do Arduino no ensino de Física.

Estas pesquisas têm como objetivo proporcionar maior familiaridade com o problema, com vistas a torná-lo mais explícito ou a construir hipóteses. [...] Embora o planejamento da pesquisa exploratória seja bastante flexível, na maioria dos casos assume a forma de pesquisa bibliográfica ou estudo de caso [...] (GIL, 2002, p. 41).

Quanto ao procedimento técnico utilizado para a coleta de dados, este foi feito através de fontes de "papel”, ou seja, através de uma pesquisa bibliográfica. Segundo Gil (2002, 
p. 44), "a pesquisa bibliográfica é desenvolvida com base em material já elaborado, constituído principalmente de livros e artigos científicos. Embora em quase todos os estudos seja exigido algum tipo de trabalho dessa natureza, há os desenvolvidos exclusivamente a partir de fontes bibliográficas".

Dessa maneira, a pesquisa seguiu as seguintes etapas: levantamento do universo de trabalhos sobre o ensino de Física com Arduino dos últimos cinco anos, definição dos temas presente nos artigos consultados, classificação e categorização dos trabalhos.

O universo de trabalho é constituído do total de artigos publicados nas principais revistas de ensino de Ciências e Física do Brasil no período de 2013 a 2017 (Caderno Brasileiro de Ensino de Física, Revista Brasileira de Ensino de Física, e Revista Brasileira de Ensino de Ciências e Tecnologia). O critério para escolha destas revistas foi baseado na avaliação da Capes (Qualis) relativo à área de ensino de ciências e matemática. Devido ao grande número de revistas, foram incluídas apenas aquelas classificadas como nacional $\mathrm{A}$, e por serem as que abordavam essa temática.

A pesquisa se concentrou nas publicações voltadas para a instrumentação no ensino de Física, através da placa Arduino. Evitando assim artigos gerais, que pudessem distorcer nossa amostragem. Portanto, evitamos artigos que abordavam o uso de Arduinos em outras aplicações, como os voltados para o curso de engenharias, robótica ou outras áreas.

Os temas foram definidos por meio da análise do conteúdo dos artigos, para enquadrá-los nas categorias adequadas. Assim, os trabalhos foram divididos em dois grandes grupos: propostas aplicadas em sala de aula e propostas para aplicação em sala de aula. Além disso, foram identificados os principais objetivos no uso desta tecnologia. Vale destacar que essa classificação não é a única possível, e que alguns trabalhos encontram-se citados em mais de uma categoria. O quadro 1 busca discriminar estes grupos.

Quadro 1 - Categorias de análise dos trabalhos revisados.

\begin{tabular}{|c|c|}
\hline \multicolumn{2}{|r|}{ CATEGORIAS } \\
\hline \multirow{7}{*}{$\begin{array}{c}\text { Propostas Aplicadas em Sala de Aula } \\
\text { (Resultados Obtidos) }\end{array}$} & $\begin{array}{c}\text { Propostas para Aplicação em Sala de Aula } \\
\text { (Resultados Esperados) }\end{array}$ \\
\hline & 1) Difundir o Arduino; \\
\hline & 2) Inovação dos laboratórios didáticos; \\
\hline & 3) Interdisciplinaridade e Contextualização; \\
\hline & 4) Potencializar a aprendizagem dos conceitos físicos; \\
\hline & 5) Tornar as aulas mais atraentes e motivadoras; \\
\hline & 6) Obtenção de dados. \\
\hline
\end{tabular}

Fonte: Elaboração dos autores.

Na seção subsequente, a partir do entendimento do cenário de constituição e visibilidade da área de atuação no ensino de Física, sublinharemos a contribuição de alguns auto- 
res quanto ao papel da experimentação e da tecnologia na sala de aula. Bem como, os desafios na utilização destes recursos, as contribuições e as possibilidades de abordagem que eles oferecem.

\section{Fundamentação teórica}

Vivemos em um mundo altamente tecnológico. A Física tem avançado muito nas últimas décadas. Porém, o ensino de Física não está acompanhando esses avanços (CARVALHO; VANNUCCHI, 1996). “[...] a velocidade do progresso científico e tecnológico e da transformação dos processos de produção torna o conhecimento rapidamente superado, exigindo-se uma atualização contínua e colocando novas exigências para a formação do cidadão" (BRASIL, 2000, p. 13).

Dessa forma, os PCN orientam como proposta curricular, o desenvolvimento de habilidades, por meio da aplicação da teoria na prática, bem como, a busca em enriquecer a vivência da ciência na tecnologia, e destas no social. Tal abordagem passa a ter uma significação especial no desenvolvimento da sociedade contemporânea (BRASIL, 2000). No entanto, a implementação dessas mudanças ao longo de quase duas décadas tem sido construída de forma lenta. Pois exige mudanças de concepções, valores e práticas, entre outros fatores que influenciam neste processo.

Dentre as dificuldades de promover mudanças coletivas na prática docente, está à implantação de estratégias com materiais diferentes do livro texto, o uso de equipamentos de laboratórios e as tecnologias da informação e comunicação. Muitos professores não utilizam essas tecnologias em suas aulas por terem dificuldade em usá-las. Ao mesmo tempo, faltam recursos físicos e humanos na escola para isso. (REZENDE; LOPES; EGG, 2004).

Outras dificuldades apontadas por professores de Física sobre as práticas experimentais são: à falta de tempo para preparar os experimentos, e dificuldade de desenvolver atividades satisfatórias devido ao grande número de alunos por turma. Além disso, muitas escolas ainda não dispõem de laboratório de ciências (REZENDE; LOPES; EGG, 2004), ou quando possuem, se queixam da falta de equipamentos e condições técnicas para usá-los. Essa situação reflete à carência de recursos que subsidiem a prática do professor, bem como, falhas na formação inicial. Esse cenário contribui para ausência da experimentação no cotidiano escolar (PENA; FILHO, 2009).

No entanto, a necessidade da abordagem prático-experimental no processo de ensinoaprendizagem de uma ciência natural, como a Física, decorre da legitimação da experimentação como a busca por elucidar a natureza: a ciência da experiência (PEREIRA; MOREIRA, 2017). Esta ação é apontada por professores e alunos, como uma das estratégias mais eficazes no processo de ensino e aprendizagem de Física (PENA; FILHO, 2009; PEREIRA; MOREIRA, 2017), pois possibilita que a passagem do real para o abstrato seja mais amena. 
Apesar desse novo olhar, a ciência continua sendo retratada através de fórmulas, definições e exercícios padronizados. No entanto, precisamos lembrar que o objetivo do ensino não é apenas transmitir informações, mas desenvolver o raciocínio do aluno, o pensamento crítico, e dar significado ao seu aprendizado (BONADIMAN; NONENMACHER, 2007).

É importante ressaltar que o trabalho laboratorial não exige necessariamente o espaço físico de um laboratório, uma vez que a prática inclui todas as atividades em que o aluno esteja ativamente envolvido. Incluindo, entre outros, o trabalho de campo. Além disso, a experimentação pode ser realizada também em sala de aula comum, desde que não sejam necessárias condições especiais de segurança (PEREIRA; MOREIRA, 2017).

Quanto à abordagem do experimento, o professor pode conduzir a realização sob diferentes enfoques. Na maneira clássica, o aluno não tem que discutir, ele aprende como se servir de um material, de um método, a manipular uma lei. Em outro tipo de abordagem, a lei é conhecida e utilizada, por exemplo, para se calcular uma medida, como em laboratórios de teste. Pode-se também investir em atividades de produção, onde ao invés do uso de princípios físicos elaborados, usam-se os conhecimentos de forma intuitiva ou do bom senso, agindo por tentativa e erro (SÉRÉ; COELHO; NUNES, 2003).

Estudantes que relataram ter professores no ensino médio que, de alguma forma, relacionavam as atividades prático-experimentais com fenômenos do mundo real, tiveram desempenho significativamente melhor, do que aqueles que focavam somente no procedimento (PEREIRA; MOREIRA, 2017).

Para Pereira e Moreira (2017), o laboratório didático é um espaço importante na escola para apropriação, consolidação e aprimoramento dos conceitos científicos. É necessário propiciar que a atividade do aluno valorize a criatividade que por vezes transpassa o próprio fazer científico. E ao mesmo tempo fomentar desafios cognitivos, se afastando da ideia de produção de verdades absolutas e inquestionáveis, que traduzem uma visão de ciência neutra (PEREIRA; MOREIRA, 2017).

No ambiente do laboratório, o aluno aprende a utilizar esquemas, aplicar relações matemáticas, ou seja, compreende melhor a linguagem simbólica na aprendizagem da Física. Ao mesmo tempo em que é estimulado a não permanecer apenas no mundo dos conceitos e das linguagens, tendo a oportunidade de relacionar esses dois mundos com o mundo empírico (SÉRÉ; COELHO; NUNES, 2003).

Portanto, a atividade experimental possibilita a vivência de uma Física mais prazerosa, intrigante, desafiadora e cheia de significados (BONADIMAN; NONENMACHER, 2007). Através da diversificação das atividades e abordagens, dando-lhes uma conotação de acordo com as atividades científicas, cria-se no aluno uma nova motivação e um novo interesse para as atividades experimentais. (SÉRÉ; COELHO; NUNES, 2003).

Por fim, diante da revolução tecnológica que vivenciamos atualmente, Rocha, Marranghello e Lucchese (2014), mostram a importância e algumas vantagens da utilização do laboratório didático aliado às novas tecnologias: 
A inserção criteriosa de recursos tecnológicos no ambiente de aprendizado através de atividades práticas de laboratório pode ajudar a aproximar mais os jovens da escola básica e até mesmo despertar vocações para as carreiras tecnológicas do ensino superior (ROCHA; MARRANGHELLO; LUCCHESE, 2014, p. 100).

Para deixar as atividades experimentais um pouco mais elaboradas, sem grandes investimentos em laboratórios, contamos com a utilização do microcontrolador Arduino como interface de automação de experimentos, por meio da aquisição automática de dados. Tal equipamento pode ser considerado uma alternativa a ser utilizada nas aulas de Física, de modo que forneça subsídios técnicos e teóricos para as práticas de laboratório a professores e pesquisadores da área.

Segundo Martinazzo et al. (2014), a sua aplicação vai desde a segurança até a automação de processos eletromecânicos.

No que diz respeito ao Ensino de Física, tem grande aplicabilidade, pois é possível ler dados de qualquer fenômeno físico detectável por sensores, ou seja, basicamente é um sistema que lê sinais elétricos em sensores expostos ao ambiente a partir de suas portas digitais e analógicas. Entre os fenômenos estudados até o momento estão: aceleração, movimento uniformemente variado, oscilação, resfriamento, evaporação e queda dos corpos (MARTINAZZO et al., 2014).

Cavalcante, Tavolaro e Molisani (2011), afirmam que o uso desta plataforma em sala de aula possibilita uma melhor interação do aluno com o conteúdo exposto, pois fará com que este se aproprie da tecnologia de forma a construir o conhecimento.

No entanto, devem-se evitar visões simplistas, como considerar que a prática experimental e/ou o uso de novas tecnologias irá solucionar os problemas do ensino de Física. Ou ainda considerar que a ciência se constrói de forma simples. Praia, Cachapuz e Pérez (2002) ressaltam as mudanças que devem ocorrer nos professores diante desse processo tão complexo:

[...] a necessária mudança de atitude dos professores, no sentido de ultrapassarem a aceitação fácil de um empirismo clássico e ingênuo, concebendo a ciência como uma simples descoberta, quer pela observação neutral, quer pela confirmação experimental escolar positiva. Importa que os professores compreendam e se consciencializem da importância do elemento cognitivo, da discussão argumentativa, que atribuam ao estudo e à reflexão um espaço indispensável para compreender as dificuldades e a complexidade que se reveste um tal processo de construção da ciência. Não se pode, entretanto, ignorar o papel do sujeito na construção do conhecimento, nomeadamente através do confronto com os conceitos e teorias aceitas em ciência (PRAIA; CACHAPUZ; PEREZ, 2002, p. 259).

Na perspectiva empirista o que mais importa são os resultados finais independentemente dos processos da sua obtenção. Nesta perspectiva, não é comum refletir no significado 
da experiência, nem nas condições teóricas e técnicas da sua produção, mas apenas no que é previsível que aconteça. Ao contrário do que esta visão propõe, o professor deve desenvolver atividades que sejam desafiadoras para os alunos, porém com um grau de dificuldade suscetível de se tornar um incentivo, e não, fonte de desânimo, desmotivação e impossibilidade de resolução (PRAIA; CACHAPUZ; PÉREZ, 2002).

Dessa forma, com atenção em alguns dos elementos há pouco mencionados, doravante abordaremos alguns aspectos importantes identificados nos artigos escolhidos para compor este estudo. Os quais foram inicialmente divididos em duas categorias: as propostas testadas em sala de aula, e as que não foram testadas. Além disso, os artigos também foram categorizados quanto ao objetivo que pretendem alcançar com o uso do arduíno nas aulas de Física.

\section{Descrição dos trabalhos: propostas didáticas testadas em sala de aula}

Os trabalhos classificados nessa categoria apresentam novas abordagens para o ensino de temas da Física. Eles foram aplicados em ambientes de sala de aula, e apresentam os resultados das experiências didáticas. Os assuntos da Física tratados foram: eletrodinâmica, termologia e termodinâmica.

Viscovini et al. (2015) propuseram um experimento em forma de maquete, usando materiais comuns e com custo acessíveis, para estudo de corrente alternada, o qual simula uma rede elétrica trifásica, com frequência variável entre $2 \mathrm{~Hz}$ e $20 \mathrm{~Hz}$. Permitindo, dessa forma, visualizar inversões na tensão elétrica através de LEDs coloridos, com o uso da placa Arduino. O objetivo principal desse projeto é viabilizar a transposição didática da teoria da corrente alternada para seu estudo no ensino médio, um tema pouco abordado em sala de aula, inclusive nos livros didáticos.

Oliveira, Alves e Barbosa (2016), objetivam trazer para sala de aula uma discussão a respeito do comportamento térmico real do aquecimento/resfriamento de uma porção de água dentro de um béquer, através da construção de um termostato programável na plataforma Arduino, controlando assim, a temperatura da água. Busca-se evitar as simplificações, por deixarem o problema muito distante da realidade, dificultando a associação entre o que é visto em sala e o que é reproduzido em laboratório.

Santos, Amorim e Dereczynsk (2017) realizaram duas atividades com alunos de uma escola pública do Rio de Janeiro, com o objetivo de auxiliar na compreensão do fenômeno de ilha de calor urbano, e ao mesmo tempo, conscientizá-los das graves consequências desse acontecimento. Primeiro, construíram pequenas estações meteorológicas, apoiadas na placa Arduino, utilizando PVC (material de baixo custo). Após essa etapa, obtiveram dados meteorológicos através do sítio do Alerta Rio. Alguns conceitos de termodinâmica, pouco abordados no ensino médio, podem ser estudados através dessa prática, tais como: a umidade relativa do ar, sensação térmica e temperatura aparente do ar. 


\section{IV.1 Levantamento de concepções}

Através da prática experimental, os alunos do $2^{\circ}$ ano do ensino médio concluíram que a capacidade térmica da fonte térmica, para pequenas quantidades de água, não é desprezível. Eles fizeram uma analogia com a primeira Lei de Newton. Quanto mais massa de água, mais o sistema resiste à mudança. Nesse caso, a mudança seria a variação de temperatura depois do desligamento do ebulidor. A atividade também serviu como motivação para irem além do que é exposto nos livros didáticos (OLIVEIRA; ALVES; BARBOSA, 2016).

Viscovini et al. (2015, p.868) concluíram que "testes realizados em sala de aula têm demonstrado uma boa receptividade pelos alunos, os quais se apresentaram motivados e interessados pela maquete".

Santos, Amorim e Dereczynsk (2017) verificaram que nestas atividades os alunos participaram ativamente, por meio de uma prática investigativa e contextualizada. Eles foram estimulados a tomarem decisões a respeito da coleta e análise dos dados, além de decidirem sobre a melhor maneira de apresentar os resultados que eles mesmos adquiriram. Práticas como essa proporcionam autonomia aos alunos e promovem interação entre eles. Ademais, consolida aprendizagens e oportuniza a obtenção de novos conhecimentos.

\section{Descrição dos trabalhos: Propostas didáticas para aplicação em sala de aula}

Os trabalhos classificados nessa categoria apresentam sugestões de práticas experimentais para as aulas de Física, apoiadas no uso do Arduino. No entanto, não dispõem de resultados de aplicação em sala de aula. As principais áreas da Física contempladas pelos trabalhos são: Mecânica, Termologia, Ondulatória, Eletrodinâmica e Física Moderna.

Rosa et al. (2016) construíram um equipamento utilizando materiais alternativos e de baixo custo envolvendo a condução de calor. A escolha do tema é justificada devido a confusões científicas comuns entre os conceitos de calor e temperatura, além de serem temas diretamente relacionados ao cotidiano das pessoas. O experimento foi realizado de duas formas distintas, ambas apoiadas pelo computador: a) utilizando termômetros para obtenção de valores de temperatura; b) inserindo sensores e a placa Arduino. A primeira prática demandou um tempo extenso para ser realizada. Tal fato pode agravar a efetivação da atividade no ensino médio. Os autores fazem a descrição do experimento, acompanhado de um conjunto de dados qualitativos.

Rocha, Marranghello e Lucchese (2014) apresentam um projeto de um acelerômetro eletrônico triaxial voltado para o ensino de Física experimental. Este dispositivo funciona conectado à placa Arduino, sendo capaz de fornecer dados numéricos de aceleração que atualizam no decorrer de uma experiência. São propostas duas aplicações: a primeira propõese ao monitoramento das variações de aceleração sofrida por um corpo em queda sujeito a força de viscosidade do ar, ao campo gravitacional terrestre e a força de um cabo elástico. A 
segunda aplicação se refere ao estudo da variação da aceleração sofrida pelo acelerômetro, quando acoplado a uma haste rígida em pontos distintos desta.

Trentin et al. (2015) descrevem o processo de construção de um equipamento didático robotizado e a apresentação da proposta didática-metodológica para abordagem dos conceitos introdutórios de cinemática no ensino médio. Para comandar e ou obter dados dos componentes é necessário que os mesmos estejam conectados ao Arduino. O equipamento foi projetado com materiais de baixo custo, de fácil aquisição e manutenção pelas escolas. $\mathrm{O}$ autor ressalta o uso da metacognição como favorecedora da aprendizagem.

Kelly, Rocha e Germano (2017) propuseram a construção de um espectrofotômetro caseiro, usando a placa Arduino, para introduzir conceitos de Física Moderna, considerando que essa disciplina é pouco abordada no ensino médio. Apesar de o experimento ser desenvolvido com materiais de baixo custo, possui boa eficiência na realização de medidas, comparada a instrumentos sofisticados. Mediante a utilização deste equipamento é possível obter o espectro de absorção de extrato de clorofila.

Cavalcante (2013) elaborou um tubo de Kundt utilizando às novas tecnologias, envolvendo o estudo de ondas sonoras. O principal objetivo desse projeto é difundir a placa Arduino como recurso para fins educacionais, contribuindo para a melhoria da aprendizagem no ensino de Física. O estudo das ondas mecânicas é a base para compreender diversos fenômenos em outras áreas da Física, como eletromagnetismo, óptica e Física Moderna.

Cavalcante, Rodrigues e Bueno (2013) desenvolveram uma sequência didática com o objetivo de explorar o funcionamento de controles remotos, equipamento que faz parte do cotidiano dos alunos. Além disso, visam difundir o uso do Arduino no ensino de Física Moderna. Para isso, atividades são desenvolvidas acoplando o receptor IR da série PNA4601M ao microcontrolador Arduino. A escolha desse objeto de estudo permite a compreensão de todo o processo de transmissão e recepção de sinais. Também é possível abordar os conceitos associados ao efeito fotoelétrico, teoria de semicondutores e a transmissão óptica de sinais.

Rocha e Guadagnini (2014) apresentam um projeto de um sensor de pressão monométrica voltado ao ensino de Física experimental, permitindo a medida da pressão de um sistema gasoso em comparação com a pressão atmosférica local, utilizando balões de látex. Este dispositivo é constituído de um transdutor de pressão piezoresistivo e uma placa Arduino para digitalização de leituras analógicas do transdutor, tratamento dos dados e comunicação digital, através da interface USB. Seu uso se mostra promissor em práticas de ensino de Física que busquem a inovação no laboratório didático, devido à possibilidade de utilizar o recurso da FTR (Física em tempo real) com uma classe demonstrativa. Como também, pelo envolvimento de estudantes em projetos interdisciplinares. A prática ilustrativa pode ser desenvolvida em uma sala de aula comum com recursos de baixo custo.

Rocha, Guadagnini e Lucchese (2017) descreveram um projeto de inovação tecnológica, que consiste na construção de um calorímetro de relaxação para medidas de 
calor específico em temperatura ambiente. Cujo delineamento é direcionado ao ensino de Física experimental, apresentando as características de constituição física e seu funcionamento. O monitoramento da temperatura e do tempo foi feito eletronicamente em tempo real por um computador conectado a uma placa Arduino. Os dados obtidos podem ser disponibilizados por tabelas e gráficos através da ferramenta de aquisição de dados PLXDAQ e a planilha ex-cel. A proposta apresentada utiliza materiais de baixo custo e objetiva a inovação dos laboratórios didáticos para ensino de Ciências ou propostas de instrumentação para ensino de Física.

Mathias, Silva e Silva (2017) empregam o dispositivo Arduino em uma inovadora e simples montagem de um analisador de pilhas recarregáveis, que possibilita a abordagem e aprendizagem de conceitos físico-químicos relacionados. $\mathrm{O}$ equipamento realiza a carga e descarga de pilhas, permitindo o cálculo da sua capacidade de carga e do seu estado de saúde. A placa Arduino funciona como acionador e aquisitor de dados analógicos e digitais do sistema físico real, enquanto o ambiente de computação Matlab, como software controlador, visualizador e analisador dos dados. O projeto desenvolvido apresenta custo bem reduzido em comparação com as versões disponíveis no mercado.

Souza et al. (2011) apresentam a placa Arduino como uma opção de baixo custo para a aquisição de dados com um computador pessoal. E sugerem duas opções simples de aplicação que comprovam a potencialidade dessa placa: o oscilador amortecido e a transferência radiativa de calor. No primeiro caso, o Arduino é usado para registrar o movimento amortecido de uma lâmina. Na segunda proposta, utiliza-se a mesma metodologia para estudar as trocas radiativas de energia.

Cavalcante, Tavolaro e Molisani (2011) divulgam diferentes modos de operar o Arduino, como uma alternativa para a obtenção de dados em experimentos de Física via porta USB do computador. Usam como exemplo de aplicação o estudo de carga e descarga de um capacitor de um circuito RC em série, através de dois procedimentos: coleta de dados num circuito convencional e num circuito automatizado.

Carvalho e Amorim (2014) expuseram uma montagem experimental para o estudo da maré atmosférica, apoiado no uso da placa Arduino. Alguns equipamentos que fazem parte do aparato experimental são: a placa Arduino UNO, um sensor duplo de pressão atmosférica e temperatura, e um escudo (shield) para Arduino, com função de armazenamento de dados em cartão de memória. Essa composição é voltada para alunos do ensino médio, e permite a abordagem de uma grande variedade de problemas de Física, como por exemplo, as oscilações barométricas. Sendo possível, explorar a comparação entre os fenômenos da maré atmosférica e da maré oceânica. Ao final da prática, os alunos podem constatar que a maré atmosférica é regida pelo sol, e, portanto, não é um efeito gravitacional.

Guaitolini et al. (2016) utilizaram a plataforma de hardware livre Arduino para automatizar o processo de coleta de dados no movimento de queda de um objeto, um experimento capaz de fornecer o módulo da aceleração da gravidade local com boa precisão. 
Foram utilizados sensores posicionados em alturas conhecidas para a obtenção do tempo, de forma mais precisa. Os autores apresentaram um breve resumo da construção e funcionamento do equipamento, assim como a descrição do circuito e o algoritmo utilizado para automatizar as medidas, contribuindo assim, para a possível reprodução por professores e alunos interessados. $\mathrm{O}$ instrumento desenvolvido permitiu obter o valor médio de $\mathrm{g}$ diferindo em apenas $1 \%$ do valor encontrado na literatura. À vista disso, os autores mostraram que o Arduino é uma ferramenta interessante para aquisição de dados e automatização de experimentos de Física.

Szmoski et al. (2018) propuseram um aparato experimental de baixo custo para estudar magnetos em queda dentro de tubos metálicos e não-metálicos. Com esse experimento é possível explorar assuntos importantes, como a queda dos corpos e indução eletromagnética. Além do mais, é factível observar que dependendo do material dos tubos, o movimento pode ser acelerado ou uniforme. O aparato é composto por um sensor ultrassônico, acoplado ao microcontrolador Arduino, que possibilita acompanhar o deslocamento do magneto em intervalos curtos de tempo. E assim, obter a velocidade e/ou aceleração. Este equipamento pode ser considerado de baixo custo, pois se mostra como uma alternativa para a realização de um experimento simples, que, muitas vezes não é executado devido à inexistência de equipamentos comumente usados nos laboratórios. Conjuntamente, traz como vantagem a possibilidade de visualização gráfica em tempo real.

Silveira e Girardi (2017) descreveram a construção e funcionamento de um kit experimental, de baixo custo para demonstrar o efeito fotoelétrico. O kit experimental foi denominado FOTODUINO, e consiste em um conjunto de lâmpadas, grade e placa (de ferro zincado ou zinco). Foi utilizada a plataforma Arduino para controle e interface com o computador, bem como um pico amperímetro com amplificador operacional de alto ganho e impedância. Os quais foram desenvolvidos para controlar o experimento e exibir os dados obtidos em tempo real. Os autores também relatam as aplicações do kit para o estudo do efeito termiônico e da condutividade elétrica do plasma. Ademais, o aparato construído viabiliza a utilização para demonstrações envolvendo eletrostática, pois apresenta grande sensibilidade às variações do campo elétrico nas proximidades da grade. A utilização da plataforma Arduino traz ainda a possibilidade do aluno realizar o experimento mesmo fora do ambiente escolar, bastando para isso acesso a internet.

Pereira, Santos e Amorim (2016) descreveram experimentos didáticos simples sobre detecção de radiação e estatística de contagens, utilizando a plataforma Arduino, os quais admitem aplicação no ensino médio e superior. Os experimentos ilustram a natureza binomial do processo de decaimento radioativo, e permite ao estudante medir as distribuições de Poisson e Gaussiana. Este tema tem sido muitas vezes negligenciado, até nos curso de graduação. No entanto, é importante sua abordagem para os alunos do ensino médio, porque a radioatividade está presente no cotidiano das pessoas. Seja através do diagnóstico e tratamento de doenças, como o câncer, ou por meio da irradiação de alimentos. Para mais, 
esse estudo auxilia na compreensão sobre acidentes radioativos e a utilização da energia nuclear. A construção desse aparato experimental se mostra vantajosa, por ser bem mais acessível que um medidor Geiger comercial, além de medir satisfatoriamente a radiação em algumas situações.

Coluci et al. (2013) desenvolveram uma montagem baseada no fenômeno da queda livre para auxiliar na ilustração do conceito de incerteza de medidas. No ensino médio, esses conceitos, apesar de relevantes, são raramente considerados. Contudo, poderiam contribuir para corrigir a visão distorcida dos alunos, de que a Física foi desenvolvida por gênios da ciência. No aparato experimental, os tempos de queda foram obtidos automaticamente pela placa Arduino e exibidos na forma de um histograma na tela do computador. A visualização em tempo real permitiu verificar o aparecimento do aspecto gaussiano.

\section{Descrição dos trabalhos: Principais objetivos no uso do Arduino}

Nessa categoria, os trabalhos foram classificados quanto aos objetivos identificados e apontados pelos autores, por meio do uso dessa plataforma, podendo um artigo ser enquadrado em mais de um critério. Foi possível identificar seis objetivos: 1) Difundir o Arduino; 2) Inovação dos laboratórios didáticos; 3) Interdisciplinaridade e contextualização; 4) Potencializar a aprendizagem dos conceitos físicos; 5) Tornar as aulas mais atraentes e motivadoras; 6) Obtenção de dados.

\section{VI.1 Difundir o Arduino}

O Arduino é uma plataforma eletrônica de código aberto baseado em hardware e software fáceis de usar. Construída para promover a interface física entre o ambiente e o computador. É basicamente um microcontrolador constituído de um microprocessador, memória e periféricos de entrada (sensores de temperatura, luz, som, umidade, etc.) e saída (leds, motores, displays, autofalantes, etc). Uma das vantagens do Arduino é a facilidade de programação, versatilidade e baixo custo. Destinada a estudantes sem experiência em eletrônica e programação, pode ser usado para construir instrumentos científicos que provem princípios físicos. Dessa maneira, pode contribuir substancialmente para despertar o interesse dos alunos pela disciplina (GUAITOLINI et al., 2016; KELLY; ROCHA; GERMANO, 2017; ARDUINO, 2018).

Santos, Amorim e Dereczynsk (2017) apontam alguns benefícios no uso da plataforma e software de programação do arduino:

O software de programação (IDE) é livre, baseado numa linguagem simples, derivada essencialmente da linguagem C/C++. Uma das grandes vantagens é a disponibilidade de uma grande quantidade de bibliotecas de programas, de acesso livre, que usadas como sub-rotinas facilitam a comunicação com os mais diferentes tipos de sensores. Devido a essa notável versatilidade como plataforma de controle e 
aquisição de dados, já existe uma extensa relação de trabalhos de aplicação da placa Arduino no ensino de Física e que podem ser encontrados na literatura da área (SANTOS; AMORIM; DERECZYNSK, 2017, p. e1505-3).

A placa do Arduino pode ser montada ou comprada pré-montada e o software para programação pode ser baixado gratuitamente. Os projetos para a montagem das diferentes placas estão disponíveis sob uma licença de código aberto, para que os usuários montem livremente suas próprias adaptações, além daquelas já comercializadas (CAVALCANTE, 2013; GUAITOLINI et al., 2016). Outro proveito dessa tecnologia é a ampliação das formas de interação com os robôs criados em projetos de robótica voltados para o ensino. (TRENTIN et al., 2015).

Santos, Amorim e Dereczynsk (2017) complementam sua abordagem, destacando outros ganhos na utilização e divulgação dessa tecnologia para as práticas educativas:

A divulgação e o incentivo à utilização da placa Arduino trará muitos benefícios às práticas educativas dos professores por oferecer riquíssimas oportunidades de contextualização através de vários projetos já existentes, muitos voltados para o ensino de Física (SANTOS; AMORIM; DERECZYNSK, 2017, p. e1505-11).

Portanto, entendemos ser relevante que o professor de Física se aproprie das novas tecnologias, em especial, a plataforma Arduino, buscando incorporá-la em suas aulas. Visto que muitas são as vantagens e diferentes abordagens que este recurso oferece, em relação à aplicação de experimentos por meios tradicionais. Destaca-se, por exemplo, a possibilidade de visualização gráfica em tempo real, favorecendo uma análise e compreensão mais profunda dos fenômenos estudados (SILVEIRA; GIRARDI, 2017).

\section{VI.2 Inovação dos laboratórios didáticos}

Muitas escolas públicas, apesar de apresentarem laboratório didático, geralmente são equipadas com itens básicos, ligados ao estudo da Física Clássica, Química e Biologia. Porém, quando se trata de equipamentos mais elaborados, como os utilizados na abordagem de Física Moderna, são quase escassos, devido, em grande parte, aos altos custos. Em contrapartida, muitas escolas possuem computadores em laboratório de informática, que poderiam ser alocados para os laboratórios de Física. Esta mudança proporcionaria o uso das máquinas em simulações e em coleta automática de dados, por meio de microcontroladores. Os quais manipulam sensores e se comunicam com o computador. Com a modernização desses espaços, as possibilidades de abordagem de diversos temas da Física no ensino médio seriam ampliadas significativamente (SILVEIRA; GIRARDI, 2017).

Com a inclusão dos computadores nos laboratórios didáticos, buscamos a construção de uma visão tecnológica inserida na solução de problemas concretos. Onde, os estudantes aprendam não somente como usar as novas tecnologias, mas também reflitam sobre as 
implicações sociais e as diversas possibilidades de utilização destas (GUAITOLINI et al., 2016).

Segundo Cavalcante, Tavolaro e Molisani (2011), o computador é uma importante ferramenta cognitiva que permite ao estudante desenvolver habilidades, organizar e sistematizar informações e construir uma interpretação do mundo que o cerca. Essa ferramenta tem sido usada no ensino de Física, como instrumento de laboratório, buscando diminuir a distância tecnológica entre a escola e o estudante.

Souza et al. (2011) destacam que tem ocorrido um aumento significativo em projetos experimentais assistidos por microcomputadores, voltadas para a sala de aula. Empresas de material didático fornecem linhas completas de equipamentos. Porém, o uso destes kits experimentais em sala de aula se torna inviável, devido a seu alto custo. Uma alternativa para inserir as novas tecnologias são equipamentos de baixo custo, como o Arduino. Que envolve diferentes portas de comunicação e periféricos do PC.

Nesse contexto, Viscovini et al. (2015), destacam a importância da escolha de estratégias apropriadas de ensino pelo professor, em busca de uma interação adequada entre os alunos, no uso de novas tecnologias:

Essas novas tecnologias surgem para auxiliar o tradicional quadro negro. No entanto, faz-se necessário a elaboração e utilização de estratégias de ensino, garantindo uma maior interação entre professor e alunos. Neste sentido, propõe-se que o professor não seja um mero utilizador das tecnologias disponíveis, mas que tenha um papel ativo em construir e experimentar juntamente com seus alunos (VISCOVINI et al., 2015, p. 857-858).

Segundo Trentin et al. (2015), para que a tecnologia seja incorporada ao sistema educacional, é necessário a criação de programas e softwares associados às disciplinas curriculares. Mas, principalmente, a estruturação de equipamentos tecnológicos apropriados para esse contexto. $\mathrm{O}$ autor também coloca a robótica na sala de aula como uma ação de inclusão digital, possibilitando que os estudantes visualizem na realidade escolar os eventos presentes no seu cotidiano.

Rocha, Marranghello e Lucchese (2014) afirmam que o acelerômetro se mostra promissor para ser utilizado em diversas práticas de ensino de Física. Tendo como objetivo, a inovação no laboratório didático, pela possibilidade de utilizar o FTR (recurso da Física em tempo real) com uma classe demonstrativa. Além disso, a utilização de sensores conjuntamente com sistemas de aquisição automática de dados representa uma possibilidade de inovação nas formas de ensinar e de aprender, integrando tecnologia, teoria e experimento.

A abordagem da Física em tempo real (FTR) permite ampliar a função tradicional do laboratório didático dos currículos atuais. A qual tem sido caracterizada como atividade complementar às aulas teóricas, ou com ênfase na aprendizagem procedimental. Com esse novo aspecto, o laboratório pode se tornar um espaço de aprendizagem mais dinâmico, 
participativo e integrado as demais disciplinas, propiciando um vínculo entre teoria e prática (ROCHA; GUADAGNINI, 2014).

\section{VI.3 Interdisciplinaridade e Contextualização}

Segundo Bonadiman e Nonenmacher (2007) um ensino contextualizado é aquele que relaciona os conteúdos em estudos com outros que fazem parte de um mesmo contexto, ou de um contexto mais amplo. Em contrapartida, a interdisciplinaridade se manifesta na possibilidade de aprofundar o tema sob diferentes facetas, valorizando suas relações com outras áreas do conhecimento. Com um ensino nessas condições, o aluno se sente mais motivado para o estudo, qualificando consideravelmente seu aprendizado.

Uma forma de desenvolver essas propostas é através da introdução de novas metodologias apoiadas no uso de tecnologias. Esse recurso é de grande relevância e potencial para a relação ensino-aprendizagem. Porquanto, é capaz de ultrapassar os muros da sala de aula, aproximando o ensino de Física à vida real. (PEREIRA; SANTOS; AMORIM, 2016). "A contextualização poderá ocorrer em diversos momentos ao se relacionar conhecimentos de Física às causas e aos efeitos dos fenômenos" (SANTOS; AMORIM; DERECZYNSK, 2017, p. e1505-5).

Viscovini et al. (2015, p. 868) citam como exemplo, algumas temáticas que podem ser contextualizados ao ensino de Física: "além dos conceitos físicos, outros assuntos muito importantes podem ser discutidos, entre eles, a matriz energética brasileira e mundial, com suas diversas fontes, renováveis ou não".

Rocha, Marranghello e Lucchese (2014) mostraram práticas que podem incentivar estudantes a trabalharem em projetos interdisciplinares, envolvendo sensores eletrônicos, microcontroladores e sua programação computacional, e os limites de validade da informação numérica experimental. Consequentemente, através desses artifícios, espera-se que os alunos desenvolvam conhecimentos sobre os temas trabalhados.

Cavalcante, Rodrigues e Bueno (2013) acreditam que trabalhos experimentais desenvolvidos por meio de instrumentos e aplicações tecnológicas, podem contribuir para explorar conceitos físicos presentes na vida dos nossos jovens, e possibilitar uma formação mais ampla, com vistas a um maior domínio da linguagem científica. Além disso, as aulas de Física tendem a se tornar mais atraentes e motivadoras.

Mathias, Silva e Silva (2017) também utilizaram uma abordagem educacional interdisciplinar em seus trabalhos, na elaboração de um dispositivo de análise de pilhas e baterias. Este equipamento beneficia o ambiente escolar, como uma forma alternativa de aplicar conceitos físicos, químicos e matemáticos por meio da inserção tecnológica.

\section{VI.4 Potencializar a aprendizagem dos conceitos físicos}

As dificuldades na aprendizagem da Física são múltiplas e as mais variadas. 
Destacamos: a pouca qualidade dos conteúdos desenvolvidos em sala de aula; o enfoque demasiado na chamada Física matemática em detrimento de uma Física mais conceitual; o distanciamento entre o formalismo escolar e o cotidiano dos alunos; a falta de contextualização com relação às questões tecnológicas; a fragmentação dos conteúdos e a forma linear como são desenvolvidos em sala de aula, sem a necessária abertura para as questões interdisciplinares; e a pouca valorização da atividade experimental e dos saberes do aluno. Alguns desses fatores são estruturais e fogem ao controle do profissional do ensino. Outros, porém, são específicos e podem ser solucionados pelo próprio professor, através de sua ação pedagógica em sala de aula (BONADIMAN; NONENMACHER, 2007).

Tem-se ensinado uma Física altamente abstrata, na qual suas aplicações, muitas vezes, não são percebidas pelos alunos (VISCOVINI et al., 2015). Esta maneira de ensinar contradiz uma Física, como ciência que trata das coisas e dos fenômenos da natureza, da tecnologia e de situações da vivência do aluno (BONADIMAN; NONENMACHER, 2007). Portanto, "há a necessidade de esclarecer essas limitações conceituais, especialmente no contexto escolar, cuja responsabilidade é voltada à cientificidade do conhecimento." (ROSA et al., 2016, p. 293)

O uso da plataforma Arduino no ensino de Física pode contribuir para uma abordagem diferente da tradicional, contribuindo para a aprendizagem de diversos conceitos. Rosa et al. (2016) afirma que o uso de novas tecnologias, como a plataforma Arduino, contribui para a discussão dos conceitos envolvidos, instiga a curiosidade dos alunos, serve como fomento à busca da pesquisa e ciência, e aproxima a escola com situações vivenciais e cotidianas.

Trentin et al. (2015) destaca que a presença da robótica como ferramenta educacional poderá auxiliar no processo de ensino e aprendizagem, pois além de ser algo atrativo e estimulante para os estudantes, permite diversas aplicações no ensino de Física.

Cavalcante (2013) mostrou que através da adaptação de um experimento clássico de acústica às novas tecnologias disponíveis, foi possível explorar diversos conceitos de acústica e características ondulatórias. Ou seja, tais recursos permitem que sejam explorados e aprofundados os conceitos de acordo com a necessidade didática.

Guaitolini et al. (2016) enfatizam as diversas etapas envolvidas no projeto de elaboração de um instrumento que visa medir uma grandeza Física utilizando conhecimentos básicos de programação e eletrônica. As etapas são: construção, solução das dificuldades no desenvolvimento, propostas de melhorias e indicação de novas abordagens. Os autores acreditam que o projeto permite o enriquecimento do processo de aprendizagem do aluno.

Rocha e Guadagnini (2014) destacam que o simples uso de recursos tecnológicos não garante vantagens no aprendizado, mas podem potencializar a aprendizagem quando utilizados em conjunto com estratégias instrucionais adequadas. As possibilidades pedagógicas dessas abordagens vão mais além, pois oportunizam formas de explorar os fenômenos naturais em situações concretas de aprendizagem de maneira integrada à teoria, na 
perspectiva de integração teoria-experimento.

\section{VI.5 Tornar as aulas mais atraentes e motivadoras}

Com o uso do Arduino, a atividade pode se mostrar mais atrativa e desenvolver a curiosidade dos estudantes em relação ao funcionamento desta tecnologia (ROSA et al., 2016), além de trazer os conceitos e aplicações dos grandes avanços científicos da Física para que os alunos estudem em sala de aula (KELLY; ROCHA; GERMANO, 2017). "Como professores, podemos motivar os alunos quanto a uma atitude investigativa frente a problemas reais" (OLIVEIRA; ALVES; BARBOSA, 2016, p. 319).

Além disso, essa ferramenta de laboratório permite diversas abordagens didáticas, como: observar o fenômeno, formular hipóteses, comparar os resultados obtidos com os previstos, reformular suas hipóteses, fazer ajustes experimentais e testá-las novamente. $\mathrm{O}$ dinamismo desse processo, aliados ao trabalho docente tendem a deixar os estudantes mais motivados e envolvidos ativamente na sua própria aprendizagem, já que a aula torna-se desafiadora (ROCHA, MARRANGHELLO, LUCCHESE, 2014; CAVALCANTE, TAVOLARO, MOLISANI, 2011). Podendo também funcionar como um elemento desencadeador de interações sociais que serve como âncora para a construção do conhecimento por parte dos estudantes. (ROSA et al., 2016).

Segundo Cavalcante, Tavolaro e Molisani (2011), ferramentas tecnológicas aliadas ao uso do computador ainda são pouco utilizadas nos laboratórios de Física:

[...] quer pela falta de informação dos professores sobre os recursos oferecidos, quer pela dificuldade em adquirir interfaces e programas de aquisição, devido ao elevado custo e também por serem sistemas fechados que impossibilitam um estudo mais detalhado de suas características e modificações que permitam adaptações para outros experimentos (CAVALCANTE; TAVOLARO; MOLISANI, 2011, p. 4503-2).

No entanto, apesar da dificuldade com os custos de alguns equipamentos, muitos experimentos têm sido desenvolvidos com materiais de baixo custo, acessíveis a maioria dos profissionais e escolas da rede pública. Silveira e Girardi (2017) propõem uma abordagem diferenciada do tradicional, através de um experimento interativo, que faz uso da plataforma Arduino aliada a uma interface gráfica, integrado com as modernas tecnologias. Eles acreditam que o fato dos próprios alunos manipularem o objeto de aprendizagem, pode motivá-los e instigá-los na busca de novos conhecimentos.

Portanto, é necessário propor novas alternativas para o ensino de conceitos físicos, entendendo que sua proximidade com o dia a dia dos alunos pode funcionar como fato motivador, tornando as aulas mais dinâmicas e interativas (VISCOVINI et al., 2015). 


\section{VI.6 Obtenção de dados}

Souza et al. (2011) afirmam que existe uma enorme variedade de placas de aquisição de dados, desde projetos simples a sofisticados. Porém, a falta de conhecimento em utilizálas, ou o preço destes equipamentos são fatores que restringem o uso da tecnologia pelos professores de Física. Além disso, alguns desses, comprados de empresas especializadas em material didático, se mostram bastante limitados na possibilidade de fazer adaptações, ao buscar novas abordagens no ensino. (GUAITOLINI et al., 2016).

Embora já exista uma comunidade de pesquisadores voltada ao desenvolvimento de projetos de instrumentação eletrônica de baixo custo, baseados em módulos sensores, para uso em laboratórios didáticos de ensino de ciências, o número de projetos sobre esses sistemas automáticos de aquisição e tratamento de dados assistidos por computador ainda é pequeno. Logo, não tem sido suficiente para estimular professores e alunos do ensino superior ou mesmo ensino médio a reproduzirem tais projetos ou construírem seus próprios equipamentos (ROCHA; GUADAGNINI, 2014).

Cavalcante, Tavolaro e Molisani enfatizam a simplicidade do uso da plataforma Arduino como aquisição e automação de dados, aliado ao custo relativamente baixo e bons resultados apresentados, contribuindo significativamente para tornar o laboratório didático de física um ambiente de investigação (2011, p. 4503-7).

Com projetos desse tipo, Rocha, Guadagnini e Lucchese (2017) visam promover maior acessibilidade às tecnologias disponíveis atualmente e suprir parte da demanda de renovação do instrumental de coleta de dados de laboratórios didáticos. Já que não se podem contar com grandes recursos financeiros para a compra de equipamentos comerciais modernos por parte das autoridades governamentais.

Vários são os benefícios de se utilizar aquisição automática de dados no ensino de ciências, tais como o enriquecimento das experiências de aprendizagem, a possibilidade de se efetuar experimentos em que a coleta de dados é efetuada em intervalos de tempo muito pequenos (frações de segundo) ou muito longos (horas), agilidade na coleta dos dados (com mais tempo para sua análise e interpretação), e a alfabetização científica e tecnológica (COLUCI et al., 2013; ROCHA; GUADAGNINI, 2014; CARVALHO; AMORIM, 2014; GUAITOLINI et al., 2016). Além de tudo, há a possibilidade de visualização desses dados em tempo real (COLUCI et al., 2013). Dessa forma, a atenção dos estudantes se volta para a compreensão dos fenômenos e para a tentativa de construção de modelos físicos que busquem explicar os fenômenos investigados (COLUCI et al., 2013; CARVALHO; AMORIM, 2014; GUAITOLINI et al., 2016).

\section{Considerações finais}

Nas seções anteriores foi realizado um levantamento de 20 artigos, que utilizaram o 
Arduino no ensino de Física. Dos quais, apenas 3 práticas foram testados em ambientes didáticos, apresentando resultados satisfatórios quanto ao uso da tecnologia. Foi evidenciado que estas práticas contribuíram para despertar a motivação, autonomia e interação entre os alunos. Além disso, intensificou o processo de aprendizagem através da contextualização e interdisciplinaridade.

O restante dos trabalhos trazem propostas didáticas de experimentos de Física utilizando o Arduino, voltados para o ensino médio. Dos ramos da Física mais abordados nos artigos, temos: 40\% termologia, 25\% mecânica, 15\% Física Moderna, 15\% eletromagnetismo e $5 \%$ ondas. Dentre estes, os assuntos mais recorrentes foram Queda livre e Condução de calor.

Em muitos casos, a escolha do tema foi justificada pela sua pouca abordagem no ensino médio. Dessa forma, o desenvolvimento de equipamentos utilizando o Arduino seria também uma forma de incentivar novas abordagens. Dentre os temas mais citados, que tinham esta característica, estão aqueles que compõem a Física Moderna, como: o estudo dos princípios físicos envolvidos na espectroscopia (KELLY; ROCHA; GERMANO, 2017); transmissão e recepção de sinais por meio de radiação infravermelha (CAVALCANTE; RODRIGUES; BUENO, 2013); e o efeito fotoelétrico (SILVEIR; GIRARDI, 2017). Outros assuntos, também considerado negligenciados no ensino médio são: detecção de radiação e estatística de contagem (PEREIRA; SANTOS; AMORIM, 2016), e incerteza de uma medida (COLUCI et al., 2013).

Foi observado que um dos ramos da Física que não foi contemplado diretamente nestes trabalhos foi a Óptica Geométrica. No entanto, apesar de não ter sido dada ênfase a uma ou outra área da Física, é importante ressaltar, que a maioria das propostas didáticas possibilitam o uso em mais de um assunto, tornando o equipamento ainda mais vantajoso.

Outra constatação, quase unânime nos trabalhos, foi a utilização de materiais de baixo custo nos experimentos. Nas escolas públicas, muitos experimentos não são realizados pela falta de equipamentos e/ou laboratórios, visto que alguns recursos implicam um custo elevado, como àqueles voltados para o estudo da Física Moderna. Impossibilitando assim, a prática experimental.

Frente a essa deficiência presente na maioria das escolas públicas de ensino médio, a maioria dos trabalhos propõem a utilização de materiais simples, do cotidiano dos alunos, de baixo ou nenhum custo, como uma alternativa para amenizar o problema e inserir a prática experimental. Foram utilizados materiais como caixas de sapato, lâmpadas, cano de PVC, compensado, latas, dentre outros. Além dos materiais comuns, foram utilizados sensores e o Arduino. Os quais, também são considerados de baixo custo pelos autores, pois sua aquisição é bastante acessível quando se comparada a kits experimentais e equipamentos tradicionais divulgados e vendidos no mercado.

Mesmo com a proposta detalhada de construção dos aparatos experimentais, muitos autores destacam a possibilidade de outras abordagens e muita oportunidade de 
contextualização, adaptando os materiais e ferramentas disponíveis por professores e alunos (ROSA et al., 2016).

Levando em conta os principais objetivos especificados nos trabalhos, os quais intentam alcançar com a utilização das propostas didáticas em sala de aula, constatamos que $50 \%$ visam potencializar e introduzir conceitos físicos, $30 \%$ buscam envolver os estudantes em projetos interdisciplinares e contextualizados, 30\% objetivam tornar as aulas mais atraentes e motivadoras, $25 \%$ buscam a inovação dos laboratórios didáticos, outros 25\% visam a medição de grandezas e obtenção de dados em tempo real, e $5 \%$ objetivam a difusão do Arduino no ensino de Física. Vale lembrar que cada prática pode intencionar alcançar vários objetivos no ensino de Física, ou seja, pode está relacionada a mais de um critério. Além disso, é possível que alguma finalidade ou característica dos trabalhos desenvolvidos, não tenham sido identificados na presente pesquisa.

É importante destacar que a maioria dos experimentos utilizou a plataforma Arduino em seus experimentos para obtenção de dados, mesmo que não tenha sido este o intuito principal. Isso se deve ao fato da ferramenta permitir a medida de grandezas físicas de forma rápida e precisa por meio de sensores. Os sensores mais comuns e utilizados nos trabalhos foram: sensor de luminosidade, receptor infravermelho IR, sensor de pressão, de temperatura, ópticos e ultrassônicos. Como os protótipos desenvolvidos possuem conexão direta com o computador, é possível a obtenção e apresentação dos dados coletados de uma experiência em tempo real (Física em tempo real - FTR). Algumas vantagens da FTR são: rapidez no registro de dados, processamento de dados complexos, e exibição dos dados em tabelas e gráficos. Permitindo ao aluno dispensar mais tempo à análise e interpretação física (ROCHA; MARRANGHELLO; LUCCHESE, 2014).

Pode-se deferir que apesar do Arduino está sendo difundido nos meios de pesquisa, seu uso ainda não atingiu o cotidiano das escolas. As restrições encontradas para o uso dessa tecnologia pelos professores, vão desde o desconhecimento até a pouca oferta no mercado nacional e o preço (SOUZA et al., 2011).

A plataforma Arduino mostra-se uma importante ferramenta para o professor em sala de aula, pelo fato de ser uma tecnologia barata, de fácil acesso a informações, ocupa pouco espaço no ambiente de aprendizagem e supri uma necessidade recorrente que é a coleta de dados, pois é possível conectar sensores e atuadores para diversas aplicações.

Além disso, as propostas apresentadas até aqui contribuem no cumprimento de uma das finalidades do Ensino Médio, estabelecidas pela Lei de Diretrizes e Bases da Educação (LDB, art. 35") "a compreensão dos fundamentos científico-tecnológicos dos processos produtivos, relacionando a teoria com a prática, no ensino de cada disciplina” (BRASIL, 1996). Portanto, a escola precisa ter o compromisso em promover a apropriação das linguagens científicas e das tecnologias digitais, bem como sua utilização.

O uso do computador tem sido adotado como agente transformador no ensino e aprendizagem da Física, buscando diminuir a distância tecnológica entre a escola e o 
estudante (CAVALCANTE; TAVOLARO; MOLISANI, 2011). Além das vantagens já citadas anteriormente relacionadas à FTR, destacamos a possibilidade de realizar o experimento fora do ambiente escolar, bastando para isto acesso a internet.

Pelo caráter experimental que a Física possui não é suficiente apenas aulas expositivas para que o aprendizado seja significativo, é necessário também uma aproximação dos conteúdos vistos com a experimentação. Muitos fenômenos físicos são fáceis de serem constatados, bastando apenas que o professor utilize as tecnologias de informação e comunicação para que este processo seja possível.

Portanto, acreditamos que a utilização de novas tecnologias no ensino de Física pode contribuir para alfabetização científica, pois representa uma forma de inovação de ensinar e aprender, através da integração entre tecnologia, teoria e experimento (ROCHA; MARRANGHELLO; LUCCHESE, 2014). Sendo capaz de contribuir substancialmente na aprendizagem, despertando a motivação dos alunos e envolvendo-os ativamente no processo de obtenção de conhecimentos. Além disso, pode auxiliar na formação integral das crianças e jovens, preparando-os para lidar com as exigências da sociedade moderna, decorrentes das constantes mudanças e avanços das novas tecnologias.

Apesar da pesquisa não fornecer dados concretos, acreditamos que este estudo possa contribuir para difundir o arduíno, como uma tecnologia de fácil utilização e baixo custo. Além de fornecer indícios para futuras pesquisas nesta área, balizadas pelo uso das novas tecnologias como uma aliada no processo de ensino e aprendizagem.

\section{Referências}

ARDUINO. Disponível em: <https://www.arduino.cc/>. Acesso em: mar. 2018.

BONADIMAN, H; NONENMACHER, S. E. B. O Gostar e o Aprender no Ensino de Física: Uma Proposta Metodológica. Caderno Brasileiro de Ensino de Física, v. 24, n. 2, p. 194223, ago. 2007.

BRASIL. Lei de Diretrizes e Bases da Educação Nacional, Lei nº 9.394, 1996.

BRASIL. Parâmetros Curriculares Nacionais: ensino médio. Brasília: Ministério da Educação, 2000.

CARVALHO, L.; AMORIM, H. Observando as marés atmosféricas: Uma aplicação da placa Arduino com sensores de pressão barométrica e temperatura. Revista Brasileira de Ensino de Física, v. 36, n. 3, p. 3501, 2014.

CARVALHO, A. M. P; VANNUCCHI, A. O currículo de Física: Inovações e tendências nos anos noventa. Investigações em Ensino de Ciências, v. 1, n. 1, p. 3-19, 1996.

CAVALCANTE, M. Novas tecnologias no estudo de ondas sonoras. Caderno Brasileiro 
de Ensino de Física, v. 30, n. 3, p. 579-613, dez. 2013.

CAVAlCANTE, M.; TAVOLARO, C.; MOLISANI, E. Física com Arduino para iniciantes. Revista Brasileira de Ensino de Física, v. 33, n. 4, p. 4503, 2011.

CAVAlCANTE, M.; RODRIGUES, T.; BUENO, D. Controle remoto: princípio de funcionamento (parte 1 de 2). Caderno Brasileiro de Ensino de Física, v. 30, n. 3, p. 554565, dez. 2013.

COLUCI, V.; PAULINO, G.; SOUZA, D.; VASCONCELOS, E. Ilustração de incertezas em medidas utilizando experimentos de queda livre. Revista Brasileira de Ensino de Física, v. 35, n. 2, p. 2506, 2013.

GIL, A. C. Como classificar as pesquisas? In: GIL, A. C. Como elaborar projetos de pesquisa. 4. ed. São Paulo: Atlas, 2002.

GUAITOLINI, J.; RAMOS, G.; SILVA, S.; GAMA, A. Avaliação do módulo da aceleração da gravidade com Arduino. Caderno Brasileiro de Ensino de Física, v. 33, n. 2, p. 619-640, ago. 2016.

KELLY, G.; ROCHA, D.; GERMANO, R. Espectroscopia para o ensino médio utilizando a placa Arduino. Revista Brasileira de ensino de ciência e tecnologia, v. 10, n. 2, p. 1-17, mai-ago. 2017.

MARTINAZZO, C. A.; TRENTIN, D. S.; Douglas FERRARI, D.; PIAIA. M. M. Arduino: Uma tecnologia no ensino de Física. Perspectiva, Erechim, v. 38, n. 143, p. 21-30, set. 2014.

MATHIAS, L.; SILVA, P.; SILVA, O. Um instrumento alternativo ao estudo de pilhas recarregáveis via Arduino. Caderno Brasileiro de Ensino de Física, v. 34, n. 1, p. 310-323, abr. 2017.

OLIVEIRA, R.; ALVES, M.; BARBOSA, V. Aquecimento e resfriamento da água, aproximados à forma real. Caderno Brasileiro de Ensino de Física, v. 33, n. 1, p. 306-319, abr. 2016.

PENA, F. L. A; FILHO, A. R. Obstáculos para o uso da experimentação no ensino de Física: um estudo a partir de relatos de experiências pedagógicas brasileiras publicados em periódicos nacionais da área (1971-2006). Revista Brasileira de Pesquisa em Educação em Ciências, v. 9, n. 1, 2009.

PEREIRA, M. V.; MOREIRA, M. C. A. Atividades Prático-experimentais no Ensino de Física. Caderno Brasileiro de Ensino de Física, v. 34, n. 1, p. 265-277, abr. 2017.

PEREIRA, A.; SANTOS, A.; AMORIM, H. Estatística de contagem com a plataforma 
Arduino. Revista Brasileira de Ensino de Física, v. 38, n. 4, e4501, 2016.

PRAIA, J.; CACHAPUZ, A.; PÉREZ, D. A hipótese e a experiência científica em educação em ciência: contributos para uma reorientação epistemológica. Ciência e Educação, v. 8, n. 2, p. 253-262, 2002.

REZENDE, F; LOPES, A. M. A; EGG, J. M. Identificação de Problemas do Currículo, do Ensino e da Aprendizagem de Física e de Matemática a partir do discurso de Professores. Ciências e Educação, v. 10, n. 2, p. 185-196, 2004.

ROCHA, F.; GUADAGNINI, P. Projeto de um sensor de pressão manométrica para ensino de física em tempo real. Caderno Brasileiro de Ensino de Física, v. 31, n. 1, p. 124-148, abr. 2014.

ROCHA, F.; GUADAGNINI, P.; LUCCHESE, M. Projeto de um calorímetro de relaxação para o ensino de Física. Caderno Brasileiro de Ensino de Física, v. 34, n. 1, p. 278-297, abr. 2017.

ROCHA, F.; MARRANGHELLO, G.; LUCCHESE, M. Acelerômetro eletrônico e a placa Arduino para o ensino de Física em tempo real. Caderno Brasileiro de Ensino de Física, v. 31, n. 1, p. 98-123, abr. 2014.

ROSA, C.; TRENTIN, M.; ROSA, A.; GIACOMELLI, A. Experimento de condução térmica com e sem uso de sensores e Arduino. Caderno Brasileiro de Ensino de Física, v. 33, n. 1, p. 292-305, abr. 2016.

SANTOS, A.; AMORIM, H.; DERECZYNSKI, C. Investigação do fenômeno ilha de calor urbana através da utilização da placa Arduino e de um sítio oficial de meteorologia. Revista Brasileira de Ensino de Física, v. 39, n. 1, e1505, 2017.

SÉRÉ, M. G; COELHO, S. M; NUNES, A. D. O Papel da Experimentação no Ensino de Física. Caderno Brasileiro de Ensino de Física, v. 20, n. 1, p. 30-42, abr. 2003.

SILVEIRA, S.; GIRARDI, M. Desenvolvimento de um kit experimental com Arduino para o ensino de Física Moderna no Ensino Médio. Revista Brasileira de Ensino de Física, v. 39, n. 4, e4502, 2017.

SOUZA, A.; PAIXÃO, A.; UZÊDA, D.; DIAS, M.; DUARTE, S.; AMORIM, H. A placa Arduino: uma opção de baixo custo para experiências de Física assistidas pelo PC. Revista Brasileira de Ensino de Física, v. 33, n. 1, 1702-1 a 172-5, 2011.

SZMOSKI, R.; DOFF, A.; LENART, V.; SCHWIDERKE, S.; FACHINI, L. Desenvolvimento de um aparato experimental de baixo custo para o estudo de objetos em queda: análise do movimento de magnetos em tubos verticalmente orientados. Revista Brasileira de Ensino 
de Física, v. 40, n. 1, e1505, 2018.

TRENTIN, M.; ROSA, C.; ROSA, A.; TEIXEIRA, A. Robótica educativa livre no ensino de física: da construção do robô à elaboração da proposta didática de orientação metacognitiva. Revista Brasileira de Ensino de Ciência e Tecnologia, v. 8, n. 3, p. 274-292, mai-ago. 2015.

VISCOVINI, R.; SILVA, D.; ÁVILA, E.; MARTON, I.; SANTOS, M.; BALISCEI, M.; OLIVEIRA, M.; SANTOS, R.; SABINO, A.; GOMES, E.; PASSOS, M.; ARRUDA, S. Maquete didática de um sistema trifásico de corrente alternada com Arduino: ensinando sobre a rede elétrica. Caderno Brasileiro de Ensino de Física, v. 33, n. 3, p. 856-869, dez. 2015. 